\title{
A Study on Establishment of Improvement Measures to Activate Korean Long-Life Housing Certification System
}

\author{
Woo, Sujin ${ }^{1, a}$ Hwang, Eun-Kyoung ${ }^{2, b}$ and Kim, Eun-Young ${ }^{3, c}$ \\ ${ }^{13}$ Researcher, Korea Institute of Civil Engineering and Building Technology, South Korea \\ ${ }^{2}$ Senior Research Fellow, Korea Institute of Civil Engineering and Building Technology, South \\ Korea \\ asjwoo@kict.re.kr bekhwang@kict.re.kr ${ }^{\mathrm{c}}$ key@kict.re.kr
}

\begin{abstract}
Keywords: Long-life housing, Long-life housing certification system
Abstract. Long-life housing is a type of housing that can accommodate the function and performance to meet the needs of society and residents by changing and replacing infill parts such as exterior parts, interior parts and facilities that have a short life and are sensitive to social and functional changes while maintaining supports such as structure and common utilities that have a long life and receive less effects of social changes. In other words, long-life housing is a type of housing that has secured durability, variability and repair convenience. Currently, it is intended to improve the life and performance of apartment houses in the country by implementing the long-life housing certification system based on the Housing Act. The purpose of this study is to review the status of long-life housing certification system and find measures to promote such system.
\end{abstract}

\section{Introduction}

\subsection{Purpose of the study}

Long-life housing is a type of housing that can accommodate the function and performance to meet the needs of society and residents by changing and replacing infill parts such as exterior parts, interior parts and facilities that have a short life and are sensitive to social and functional changes while maintaining supports such as structure and common utilities that have a long life and receive less effects of social changes. In other words, long-life housing is a type of housing that has secured durability, variability and repair convenience. Currently, it is intended to improve the life and performance of apartment houses in the country by implementing the long-life housing certification system based on the Housing Act.

Accordingly, the purpose of this study is to review the status of long-life housing certification system, find out and analyze its problems accordingly, and seek measures to promote such system.

\section{Theoretical Review}

\subsection{Background and necessity of long-life housing}

Recently, the portion of apartment houses among the total housing in Korea has been sharply increasing as it increased from 37.5\% in 1995 to 59\%, which is equivalent to 8,360,000 units, in 2010. The average life span of common housing in a couple of major advanced countries is 128.04 years in the UK in 2003, 121.3 years in Germany in 2002 and 71.95 years in the US in 2003. The average life span of common housing in Korea is very short with 26.95 years in 2005 compared with the aforementioned countries. A short average life span of common housing in Korea is attributed to a shortened functional and social life span (variability and repair convenience) rather than a physical life span (durability).

Long-life housing seeks the durability, variability and repair convenience of common housing. Durability aims at ensuring a physical long-life span of a long-lasting common housing structure, and variability aims at ensuring social and functional long-life span satisfied with the needs of society and residents. Also, repair convenience aims at ensuring efficient long-life span maintaining a good quality of home performance.

Thus, it is necessary to devise measures to lengthen the life span of durable and repairable comm 
on housing in order not only to respond to various changes in the demographic structure of society a nd users' demands and needs but also to reduce a waste of finite resources arising from early allout demolition and reconstruction and unnecessary social costs by constructing durable apartment $h$ ouses.

\subsection{Outline of long-life housing-related laws and regulations}

Long-life housing is specified in Article 65-2 (Certification Objects and Ratings in Long-life Housing) of Regulations on Housing Construction Standard, etc and Article 16 or 22 of Rules on Housing Construction Standard, etc. based on Article 21-6 (Long-life Housing Construction Standards and Certification system) of the Housing Act as the higher law. Specific Long-life Housing Construction and Certification Standards (Public Notice No. 2014-847, Ministry of Land, Infrastructure and Transport) were publicly announced on December 24, 2014 and have been used as the current standards.

Table 1 Long-life housing certification-related laws and regulations

\begin{tabular}{l|l}
\hline \multicolumn{1}{c|}{ Classification } & \multicolumn{1}{c}{ Contents } \\
\hline Housing Act & $\begin{array}{l}\text { Article 21-6 (Long-life Housing Construction Standards } \\
\text { and Certification system, etc.) }\end{array}$ \\
\hline $\begin{array}{l}\text { Regulations on Housing Construction } \\
\text { Standard, etc }\end{array}$ & $\begin{array}{l}\text { Article 65-2 (Certification Objects and Ratings in } \\
\text { Long-life Housing, etc.) }\end{array}$ \\
\hline $\begin{array}{l}\text { Rules on Housing Construction } \\
\text { Standard, etc. }\end{array}$ & Article 16 or 22 \\
\hline $\begin{array}{l}\text { Long-life Housing Construction and } \\
\text { Certification Standards }\end{array}$ & \\
\hline
\end{tabular}

\section{Certification Status of Korean long-life Housing}

\subsection{Analysis of certification status of long-life housing}

Long-life housing certification system is composed of the items and their points such as 35 points for durability, 35 points for variability and 30 points for repair convenience (15 points for exclusive use area and common area respectively).

Table 2 Review and analysis of long-life housing by certification items

\begin{tabular}{c|c|c|c|c|c|c|c|c}
\hline \multirow{2}{*}{$\begin{array}{c}\text { Total } \\
\text { applications } \\
\text { for }\end{array}$} & \multicolumn{2}{|c|}{$\begin{array}{c}\text { Average } \\
\text { certification rating }\end{array}$} & \multicolumn{2}{|c|}{ durability } & \multicolumn{2}{c|}{ variability } & \multicolumn{2}{c}{ repair convenience } \\
\cline { 2 - 9 } certification & rating & point & rating & point & rating & point & rating & point \\
\hline 43 projects & normal & 51 & 3 & 20 & 4 & 12 & 4 & 9 \\
\hline
\end{tabular}

Every item is classified into a rating of 1 to 4 depending on its point. As shown in Table 2, the number of certifications of long-life housing is a total of 43 up to July 2015 since Long-life Housing Construction and Certification Standards were publicly announced on December 24, 2014. All projects that applied for certification received normal rating. Only one project got the highest score of 56 points, 21 projects got the lowest score of 50 points, and the other 21 projects got the average score of 51 points, which means that almost all projects got 50 or 51 points.

As the results of an analysis of long-life housing by certification items, the most frequent rating in durability is a rating of 3 ; the case of variability is a rating of 4 , and the case of repair convenience is a rating of 4 in exclusive use area and common area alike. Consequently, it is found that current long-life housing mostly has a rating of 3 or 4, the lowest ratings, in durability, 
variability and repair convenience altogether.

\subsection{Analysis of problems with certification status of long-life housing}

A majority of current certified long-life housing has a rating of 4, a normal rating, and this long-life housing is currently certified through adoption of only essential items pertaining to mandatory standards. Long-life housing with a normal rating has the advantage that contractors can feel free to work without being further burdened due to additional inexpensive construction cost. However, long-life housing with a normal rating is insufficient to be entitled to the name of long-life housing. Where the certification is hardened into a normal rating because of adoption of only essential items, long-life housing is feared to be meaningless. Thus, to acquire a certification above a good rating and to improve a long-life housing level, an interview survey of experts and an analysis of certification data were conducted to identify the problems inherent in each item.

In the case of durability, under the current long-life housing certification standards, the condition of chloride content for high ratings is set at $0.2 \mathrm{~kg} / \mathrm{m}^{3}$ or less, which is different from normal concrete structure and design standards. As an additional cost is incurred in an item of chloride content to receive high ratings above an excellent rating, its condition is currently set at $0.3 \mathrm{~kg} / \mathrm{m}^{3}$ or less, which is equivalent to a rating of 4 .

In the case of variability, it is found that, as long-life housing is accustomed to applying a bearing-wall type structure like general common housing, it bears the burden of converting its structure into a flat plate structure or reinforced concrete frame structure. Also, the increases in cost following an application of lightweight drywall members and parts and on slab plumbing system and an increase of floor height is identified as the factors that prevent the satisfaction of the standards for a rating of 3 or higher in the item of variability.

In the case of repair convenience, a burden of cost, a reduction in exclusive use area and a slight increase in construction cost caused by the securing of extra space in both exclusive use area and common area are identified as the factors for avoidance of high ratings.

\section{Search of measures to improve long-life housing certification system}

To acquire a certification above a good rating and to improve a long-life housing level, short and long-term improvement measures are deemed necessary.

In the short term, it is imperative to identify the problems among the items of durability, variability and repair convenience in the current standards mentioned above and to readjust the evaluation standards and items, and, based on this, to devise measures to improve a long-life housing level. Also, in the long term, it is deemed to a measure to improve the current certification system by unifying the current 4 ratings such as most excellent (90 points), excellent ( 80 points), good (60 points) and normal (50 points) into one rating higher than a good rating or by dualizing them into a good rating and an excellent rating.

\section{Conclusion}

Long-life housing aims to save finite resources and energy, to increase the value of personal assets and to reduce citizens' housing operation and maintenance costs by securing a good quality housing inventory on a national level.

So, to promote a diffusion of long-life housing that people sympathize with and deem necessary, it is necessary to take a gradual approach to solving problems occurring in this current stage and to establishing efficient systems.

\section{Acknowledgement}

This study result is a part of the results of a research on residential environment research project conducted by Korea Institute of Civil Engineering and Building Technology in 2015 under the sponsorship of Ministry of Land, Infrastructure and Transport (Task number: 15RERP-B082171-02000000). 


\section{References}

[1] Handbook for Long-life Housing Certification System, Korea Institute of Civil Engineering and Building Technology (2015)

[2] Development for a diffusion model of cost-effective long-life housing, Korea Institute of Civil Engineering and Building Technology, Ministry of Land, Infrastructure and Transport (2015)

[3] Managerial strategy according to the life-cycle of common housing, Korea Institute of Civil Engineering and Building Technology, Ministry of Land, Infrastructure and Transport (2013)

[4] Final report on research and development of common housing technologies for long-life housing with durability and variability, Korea Institute of Civil Engineering and Building Technology, Ministry of Land, Infrastructure and Transport (2010)

[5] Comprehensive guidelines for long-life common housing research team, Korea Institute of Civil Engineering and Building Technology (2010)

[6] Current status of certifications under Long-life Housing Certification System, Korea Institute of Civil Engineering and Building Technology (2015)

[7] S.J Woo, E.K Hwang and E.Y Kim: Study on the Improvement Plan for the Revitalization Long-Life Housing Certification System, Paper collection, Academic Conference, Architectural Institute of Korea: Vol.35 No.2 (2015)

[8] Ministry of Government Legislation http://www.moleg.go.kr/ 